\title{
Being-with Media: Encountering the moving image in physical space
}

\author{
Kenneth Feinstein \\ Sunway University \\ Centre for Research-Creation in Digital Media \\ Kuala Lumpur, Malaysia \\ kenf@sunway.edu.my
}

\begin{abstract}
The development of the images and imagery has taken a long journey from Renaissance painting. As technology has helped it develop, it changed in how it relates to us and how we relate to it. Imagery has moved from presenting allegorical stories to viewers to interacting with us in physical space. This paper presents an interpretation of these changes from a perspective of how media art has developed. It looks at how it has stopped talking to us and turned into a system that brings us face-to-face with Otherness. After laying out its theoretical grounding the paper goes on to analyse the work Post Box Cinema to see how it exemplifies these ideas.
\end{abstract}

Post-media. Media theory. Media art. Media archaeology. Emanuel Levinas. Peter Weibel.

\section{INTRODUCTION}

As we transform from an era defined by having created the media to our developing position of a post-media or with-media age our understanding and relationship to ourselves and our systems of meaning are changing. We need to look at where we are how we understand our situation and from there ask where are we going and what does that mean for us. In this paper, I will use the example of a single media work, Post Box Cinema, to ask these questions.

Media theorists such as Peter Weibel and Siegfried Zeilinski are already declaring us in a post-media age. They are saying that we live in a world where everything has been defined by our relationship to media. This doesn't just mean that we see new forms as media, but that our understanding of past works is now redefined by our understanding of what media is. As Weibel said:

\footnotetext{
We might even go so far as to say that the intrinsic success of the new media resides less in the fact that they have developed new forms and possibilities of art, but that they have enabled us to establish new approaches to the old media of art and above all have kept the latter alive by forcing them to undergo a process of radical transformation (Weibel 2012).
}

Where other theorists decry what we have lost or proclaim a bright new world because of the superiority of code and the apparatus that runs it, what Weibel is telling us that the new technology has redefined the conditions that we live; that media no longer lives in the old definitions of art. From this the old ways of understanding how we relate to media and how it relates to us changes.

We traditionally saw art as only painting, sculpture and architecture, everything else was merely craft. We can still see this reflected in early editions of the standard art history texts by Jansen, Gardener or Gombrich. What gave traditional art priority was their relationship to aesthetic thinking and an ordering and representation of the world similar to natural philosophy. It had meaning because it was seen as part of the Cartesian division of the metaphysical from the body. In The Space of Literature, Maurice Blanchot only addresses art through writing and the author. Here he defines art as separate from life, the world lived. It is this separation, which allows us to have the distance needed to reflect back on life and therefore give it meaning. Painting and sculpture can enter into this same relationship through their unique position of uniqueness and the presence they command to the viewer. Meaning is found in a lack of engagement with the world. It is a view of the function of culture as that which primes us for action, but can never have a direct effect. We observe and then chose to take action or not. Weibel tells us that the elevation of these three arts to craft to art happens during the Renaissance, when the image starts to move off the wall and into the frame. Where a mural takes 
up all our field of vision, becoming an overpowering view, the framed image becomes a window creating a view that is easily taken in. The frame becomes a distancing device, creating the needed separation from the image to allow us the godlike position to pass judgement on what we see. Meaning rests in the image because we have enclosed it. This is what we call the Window Metaphor (Belting 2011), when we look at paintings as if we are looking through a window onto another world on the other side. Not only does it assume that we accept the image in the fame as containing a reality, but more importantly it means that the relationship between the work and viewer must always be separated. We are expected to gain meaning by reflecting, from a distance, on the scene presented in the image. Our ability to judge the work is based on this omniscient separation from the image. The medium becomes the enframer and container of the message. In this classic concept of art, our relationship is one of placing us in the position of the other in order to allow us to pass judgement on the world. Otherness is seen as different from life and it is this difference that valorises the ability to pass judgement. This comes from an idea of otherness as separate from us and then detached from life. It is one where the power of the other is based on its relationship back to the self. It exists only to be in reflection to being as self.

\section{OTHERNESS AND BEING-WITH}

Our relationship with art and then media has changed as our understanding of Otherness has changed. In a post-war environment we have come move very distinctly away from a Cartesian view of the individual. Taking on concepts from thinkers such as Martin Buber \& Emmanuel Levinas the idea of our mutual responsibility to the 'other' developed. It also became enshrined in the idea of crimes against humanity and medical ethics. Our idea of our place in society moved away from Hobbesian view of competing individuals to one of mutual responsibility. With Levinas our view of ontology developed into understanding that the idea of 'being' brought forward in Being and Time depends and yet stops short with the importance of the idea of being-with. Heidegger does posit that being can only exist within a context defined by a relationship with others. He talks about being-with and Being-with-the Other, yet he also fails to develop these ideas beyond its impact on the self. We must interact and make accommodation to others, but for Heidegger this takes us away from an authentic experience of Being. What Levinas' ontology does is define our relationship to the other not as just a context in which we operate, but rather as a relationship that we are defined by (Levinas et al. 1996). It is a relationship that exists before each of us as individuals exist; it is the context that allows us to be. This means that our existence as self (being) is created out of our relationship with the 'other'. Because this relationship defines and creates us it means that we bare a responsibility to this 'other' to enable 'being' to exist and thrive. This becomes the ethical impetus. Our place in the world is not singular as much as unique within a context (Levinas 1981).

This idea of existence being a context changed not only how we saw the world, but also how we created works that talked about the world. We have envisioned timed-based media as an extension of painting. Screens are canvases where the images move - nothing more nor less. Moving images are tied to the technology that displays it. We have always looked at the history of the moving image as part of a continuum from easel painting to photography, to cinema, and finally to television and computers. On first blush it seems to make sense, but of course, as we take a closer look at the development of these technologies, our historical timeline breaks down. This way of understanding media art has limited how and where we encounter it. How we see and encounter images is an active question for the practitioners of this form, from the beginning of media art.

\subsection{Media art and a drive towards the experiential}

This understanding of our relationship to the 'other' started to be reflected in the works of certain artists. As Deleuze says in Cinema I: The Movement Image, how we experience images has much to do with how we understand the world. That our changing relationship to images reflects our changing relationship to each other and the physical environment (Deleuze 1986). Some artists tried to make kinetic work that required interaction, while others tried to breakdown the relationship of the image to the viewer. Beginning with Line Describing a Cone (1973), Anthony McCall began to turn the moving image into sculpture through the use of projection. Nam June Paik created sculptural works like TV Buddha (1974) and Electronic Superhighway (1995) where the physicality of the video screen was fundamental to the work. These works broke down the separation of the image from us, making the space of the image and our space one. At the same time as media technology developed, so did its relation to our daily lives. It became a part of how we relate to and imagine the world. It has lost its separation from us as it has helped become the definer of reality. Yet, for the most part, media art is still stuck in the form of spectacle, as in projection mapping, or ways of adapting the existing language of fine art and the window trope. 
Media art as we now know it is experiential. As such, we cannot look at it from a distance in order to make sense of it; we have to experience as a presence. We are with it in the now, we react to it and in some cases, it reacts back. Yet, we always have be with the work and not just look at it. This creates a relationship not of judgement, but rather of dialog. The meaning of the world is not presented or explained to us, but rather we extract it from being part of the work. This is what we mean by being paralogical. Athanasius Kircher's Metaphor Machine (1646) has been described as the first interactive work (Zielinski 2006). It created experiences to present tangible metaphors from religion to its public. Today's technology has developed to be conversational with us. It doesn't present meaning to us, rather, we interact with it to derive meaning. The works in this exhibition exemplify this new way of being with images so as to create meaningful experiences. They are works that enter into dialog with us through time and space. In some of these works, issues such as time in the form of history are addressed. In others, the physicality of the image in space is fundamental to how we see and experience the work. In all cases, our relationship to the work takes on a new perspective, one of being-with and interacting with the work in new ways.

With the coming of digital technology the relationship that we have to the image has transformed. The experiential has moved to the fore, transforming how we understand our relationship to media. Writers such as Lev Manovich have mainly looked at this transformation through the relationship of software to production and the image to the screen. But with the development of projection mapping and multiscreen montage we are starting to see that leave the frame and engage us in physical spaces. A direction which can be mapped back to Kircher's Metaphor Machine. As possibly the earliest documented media artwork it was experiential in nature. The viewer would walk into a room where they would see an image that showed their body, but a different head. The idea was to present a metaphorical and moral image. If one sees their body with the head of a lion or donkey they will receive a different message. Moral lessons were being presented through metaphorical language in a personal experiential way. As a device the Metaphor Machine stands between alchemical practice and media installation, with the former focused on individual transformation and the latter on communicating to a public. As a practice, devices like Kircher's moved away from a mainstream of art practice until a 20th century renewal of interest in alchemical practice in the arts. Starting with Duchamp and his large glass and moving through to Yves Klein with his immaterial performances through to projection works Krzysztof
Wodiczko and Shimon Attie, a movement away from the hierarchy of artwork to viewer has been developing. Today artist such as Theo Watson, Marc Lee, Team Lab, Erika Tan, and Isaac Julien are rethinking how we see and experience images.

\section{POST BOX CINEMA}

As an example of how our relationship with media that is starting to move into one of being-with let us look at the work Post Box Cinema. This work consists of a reproduction of a postal box that plays a video in its own shadow. The video makes up the entire shape of the shadow and physically touches the post box. The idea of this is present a relationship between the video image and the physical work (Figure 1). The physicality of the work is central to it. Where images in architectural spaces such as malls can be used screens to hide distract us from the view of the building in this work this work there is a string linkage between the object and the projected image.

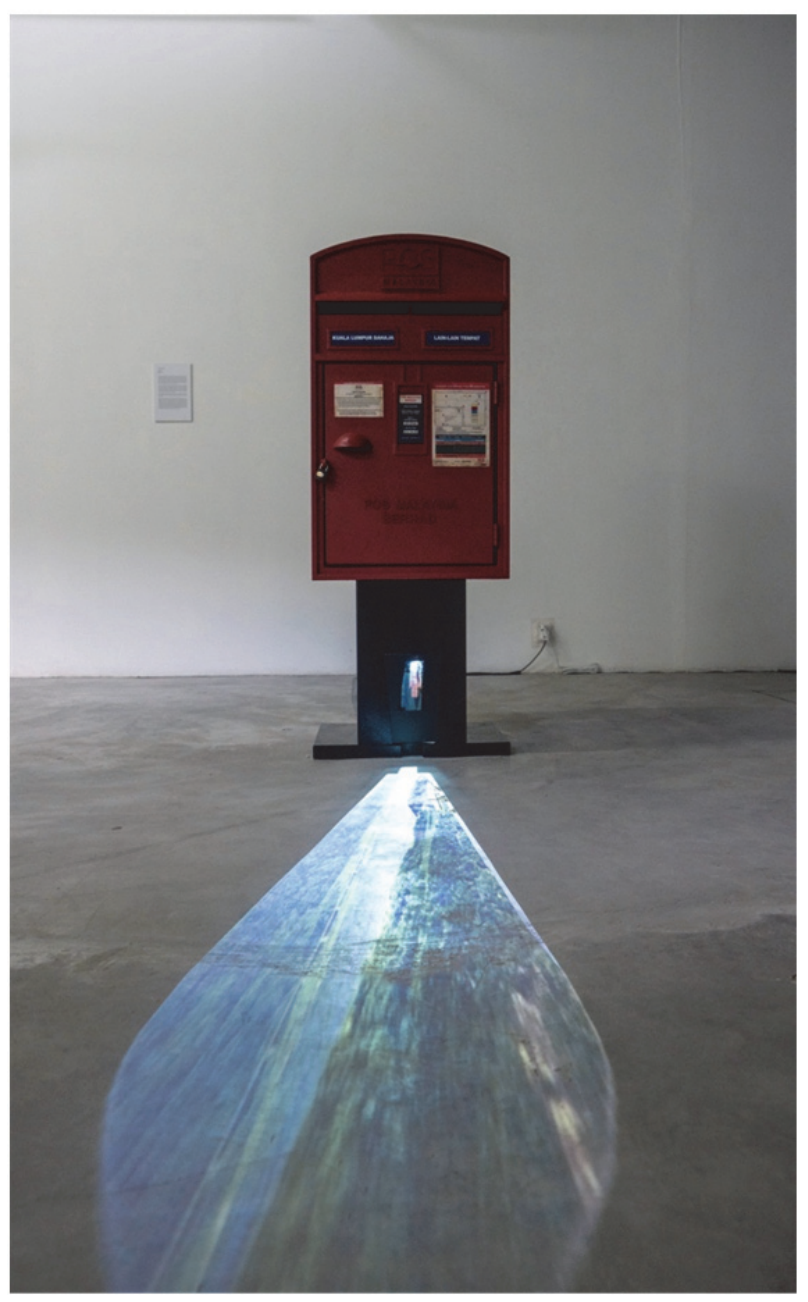

Figure 1: Post Box Cinema installed in the exhibition Paralogical Machines at Wei-Ling Contemporary, Kuala Lumpur, Malaysia, 2019. 
The language of the work is based on an idea of a shadow representing a buried idea lying behind the physical object. While we tend to think of light in general and especially sun light in particular as revealing, here it the shadow presents what is supposed to be hidden form us. The idea of shadow as representing the unconscious is a longstanding trope found in film and popular culture. It is this that the work plays off of. This allows the conceptual jump of the shadow's role in the work to be understandable for the audience. The idea of the shadow as representing unconscious motivating source was the first part of this project. Coming from an earlier series of works titled The Shadows of Time, the concept here is one where the revealed images are made to speak of our relationship to nature. How the idea of landscape is one of wanting to possess and tame nature so that it fits our ideals of beauty. These are ideals developed in the Renaissance, but derived from Greek and Roman art (Schama 1995). This desire to transform nature into something that is idealised is reflected in Romantic and Hudson River School paintings as well as landscape architecture of grand estates in the 18th and 19th centuries as well as farms/weekend houses today. The desire of Western culture to capture nature and turn it into a pleasing image is what we see in the shadow. The video is derived from images taken around Mt. Rigi in the Swiss Alps. Rigi was chosen because it was part of the Grand Tour. It was the first mountain to have a cog railroad and was visited by many notable figures of the 18th and 19th century. The Grand Tour may have started as a pilgrimage for Northern Europeans to see the classic cultural artefacts of Italy, but because it ended up including trips through the Alps, it ended up having a direct impact on both the development of the sublime and the invention of photography. The early works on the modern idea of the sublime by Anthony AshleyCooper and John Dennis directly referenced the Alps. While Henry Fox Talbot writes that he first came up with the idea of photography while visiting Lake Como. This nexus of theory, technology and desire found in the Alpine image is why it was used as the source of the shadow image.

Further locating the idea or the experience of the sublime in to nature is in itself a form of projection. It takes a non-physical state and casts out into an object outside of the self. Projection is recognised in psychology and it is how the shadow is cast on the floor in this work. To project is to send out what is contained inside in the form of an image so as to create relationship to that image. It through this relationship that we hope to create meaning.

If a shadow was to be projected out into an environment it had to be tied to an object so that it had meaning for a public. A dislocated shaped in a space is just an oddity devoid of meaning unless it is tied to an object that a) gives it context and b) is common enough to make sense in our environment. The shadow has to have a source and that source has to be something we can relate to. While different objects were thought of, ones from the home, office or street, the post box made the most sense for a few reasons. Obviously, it is a very common object, yet iconic in each of our locals. We are all familiar with what our own national post boxes look like. Also because of the status of the postal system it is an object that will not be disappearing in the near future. Where a phone booth has been iconic in the past they are no longer common because of the changes in telephone technology. The postal system is an important part of how the government operates. It is needed to communicate with the government itself. The timestamps of a postmark can be used as proof that as to when a document first existed or as proof that a document was sent to a person. Governments set up public postal systems as an important form of open communication from and to its citizenry. Article One of the US constitution gives Congress the power to establish post offices. The creation of postal systems was seen as an important part of modern liberal democracy. The idea of the post box was that it is symbolic of this idea of the modern liberal democratic system as we know it. More importantly, it is an object that we take for granted. That it seems almost invisible in its commonness made its choice even more logical.

For this work to have meaning the everyday object and the shadow/projection must present a sense of dislocation to the audience. It calls itself out because it is so common, allowing for its distortion to have impact. Because of what a post box is, what it symbolises to our society and its commonness, it became the object that the work would be centred around.

The post box symbolises our normal daily life and the ideology of the modern liberal state that this life is based on. The shadow represents a view of a natural world that we can determine and shape into idealised perfection. The shadow represents our desire to be able to control the world so as to bring this idealised fiction into reality. In this way the shadow presents an unconscious desire to dominate the world that motivates actions in our world today. It points to our buried impulses towards control and fear of the catastrophic. As a whole it becomes a thing in the world that we interact with. It exists in relation to us. As a work it makes sense when it is presented outside the art context of museum or gallery in a way different from a painting or photograph. As an object installed in the world it takes on a stronger feeling of uncanniness and wonder. It moves away from a work to be seen as different from the world to being-with the world. 


\section{CONCLUSION}

What we called the mass media age was one where works were created along the lines of established forms and genres. We had formulas that we turned to guarantee that our messages were getting out. These forms, such as film language, were developed to speak to a mass audience. This mass media helped create a sense of belonging to its viewers. It was meant to create a common baseline that we could call national identity and culture. In a past media situation we have lost the masses and replaced them with multiple and ever-changing micro-audiences. The power of the work designed to address the mass audience is waning. As our media becomes part of our environment and personal lives our relationship to it has changed. It needs to talk to us instead of at us.

The idea that at its heart media as we know it is based on a form of interaction with Otherness was first brought forward by Vilém Flusser in Into the universe of technical image (Flusser 2011). From photography to using smartphones, our basic relationship with technology is one of interaction with it and through it to others. A relationship to Otherness is inherent in very function of the technologies. These ideas are being picked up by some media artists. They are trying to create works that relate to us in a form of being-with as opposed to talking at. Post Box Cinema is an example of the attempt to make a unique work conversational within a post media world.

\section{REFERENCES}

Belting, H. (2011) Florence and Baghdad: Renaissance art and Arab science. 1st English language edn., Belknap Press of Harvard University Press, Cambridge, MA, p.303.

Deleuze, G. (1986), Cinema, 2 vols. University of Minnesota Press, Minneapolis.

Flusser, V. (2011) Into the Universe of Technical Images. University of Minnesota Press, Minneapolis.

Levinas, E. (1981) Otherwise Than Being Or, Beyond Essence. Martinus Nijhoff Philosophy Texts, xiii, p.200.

Levinas, E. et al. (1996), Emmanuel Levinas: Basic philosophical writings. Studies in Continental thought. Indiana University Press, Bloomington, xx, p.201.

Schama, S. (1995), Landscape and memory. 1st edn., A.A. Knopf, New York, xi, p.652; p.37 of plates (some folded).

Weibel, P. (2012) 'The Post-Media Condition', Mute.

Zielinski, S. (2006), Deep Time of the Media: Toward an archaeology of hearing and seeing by technical means. Electronic culture: history, theory, practice. MIT Press, Cambridge, MA, xiv, p.375. 